RESEARCH REPORT

\title{
Maternal education, lone parenthood, material hardship, maternal smoking, and longstanding respiratory problems in childhood: testing a hierarchical conceptual framework
}

Nick Spencer

J Epidemiol Community Health 2005;59:842-846. doi: 10.1136/jech.2005.036301

Background: Maternal smoking and low socioeconomic status are known to be associated with each other and with longstanding respiratory problems in childhood but their interrelation has received little attention. In this paper, the interrelations is studied using a conceptual hierarchical framework among children aged 0-11 years in a representative sample of British households with children.

Method: With data from the family and children study, this paper tested a conceptual hierarchical framework, in which maternal education acting through lone parenthood would influence material hardship and all three would have effects on maternal smoking increasing the risk of children's longstanding respiratory problems.

Correspondence to:

Professor N Spencer,

School of Health and

Social Studies and

Warwick Medical School,

University of Warwick, Coventry CV4 7AL, UK; n.j.spencer@warwick.ac. uk

Accepted for publication 29 April 2005
Results: Among children 0-2, maternal education and material hardship had indirect effects on respiratory problems mediated through more proximal variables. After adjustment for maternal education, the effect of lone parenthood was partially mediated through material hardship and maternal smoking. Adjustment for socioeconomic status variables attentuated but did not eliminate the effect of maternal smoking (odds ratio $=2.04,95 \%$ confidence interval $=1.30,3.20$ ). Among children 3-11, the effect of maternal education was partially mediated through proximal variables. Lone parenthood and material hardship had indirect effects only. Adjustment for confounding eliminated the effect of maternal smoking (odds ratio $=1.06,95 \%$ confidence interval $=0.88,1.26$ ) .

Conclusions: Reducing childhood longstanding respiratory problems will require attention to background socioeconomic status factors in addition to maternal smoking.
$\mathrm{P}$ assive inhalation by young children of environmenta tobacco smoke is associated with an increased risk of a range of adverse outcomes. ${ }^{1-3}$ Systematic reviews of the effect of passive smoking on respiratory tract conditions in infancy and early childhood, ${ }^{4}$ and school aged children, conclude that parental smoking, particularly maternal smoking, has an effect on asthma, wheeze, cough, and other respiratory problems independent of potential confounding factors. The effects are greater in infancy and early childhood than in later childhood. ${ }^{1}{ }^{5}$

Adverse social and environmental factors have been shown to be associated with a higher risk of respiratory tract conditions in infancy ${ }^{67}$ and later childhood, ${ }^{89}$ independent of parental smoking. Severity of asthma, ${ }^{10}$ and of wheezing, ${ }^{11}$ has been reported to show a social gradient. Maternal smoking in developed countries has become closely linked to low education, ${ }^{12}$ material disadvantage, ${ }^{13}{ }^{14}$ and low socioeconomic status. ${ }^{15}{ }^{16}$ Qualitative studies ${ }^{17-19}$ have reported that smoking among low income women is a way of coping daily hassles and stress and a recent quantitative study ${ }^{20}$ of socioeconomic disadvantage, parenting responsibility, and women's smoking concluded that smoking is embedded in the socioeconomic circumstances of the lives of low income white women.

While systematic literature reviews seem to rule out significant confounding of the impact of parental smoking on childhood respiratory conditions by socioeconomic status, ${ }^{145}$ the interrelation of parental smoking, social factors, and childhood respiratory conditions may be more complex with parental smoking acting as both a mediator of the effect of socioeconomic status and an independent predictor. Social factors, such as education, income, and material disadvantage, do not exert a direct effect on the child's respiratory tract but are likely to act as distal factors structuring the development, maintenance, and impact of more proximal factors such as smoking. ${ }^{21}$ Multivariate models that treat distal and proximal factors as temporally and hierarchically equivalent are inadequate for analysis of complex hierarchical relations and may produce misleading results. ${ }^{22}$ Multivariate models informed by a conceptual framework that incorporates a hierarchical approach provide a method of studying these complex relations. ${ }^{622}$

An additional problem when considering the interrelation of socioeconomic status and health is that different components of the constellation of social factors contributing to socioeconomic status may impact differently, and independently of each other, on particular health outcomes. ${ }^{23}$ For example, parental lack of money for basic needs has been shown to exert an effect on the health of young children independent of maternal education. ${ }^{24}$ A conceptual framework based on a hierarchical approach needs to take account of the potential for certain socially related factors such as lone parenthood to act as both independent predictors and mediators of the effect of other more distal socioeconomic status variables.

This paper uses data from the 2001 sweep of the family and children study (FACS), ${ }^{25}$ based on a representative sample of British households with children $0-18$ years, to explore the interrelation of maternal education, lone parenthood, material hardship, and maternal smoking and their impact on parent reported longstanding chest problems in two age groups, children $0-2$ and 3-11 years. A conceptual model based on a hierarchical approach ${ }^{22}$ is tested using the data to study proximal and distal determinants of longstanding chest problems in children of differing ages. 


\section{METHODS}

\section{The conceptual framework}

A conceptual framework (box 1) was developed to represent the hierarchical interrelations among variables, commonly grouped under socioeconomic status in child health research, maternal smoking, and longstanding respiratory problems in children aged 0-11 years. Maternal education, commonly used as a socioeconomic status proxy ${ }^{26}$ and consistently associated with child health outcomes, ${ }^{27}{ }^{28}$ was seen as the most distal variable representing socioeconomic status in the mother's early life course (level 1 in box 1). Lone parenthood $^{29}$ is associated with low educational attainment and is temporally proximal to education (level 2 in box 1). Material hardship in the UK is associated with both low educational attainment $^{30}$ and lone parenthood ${ }^{29}$ and is likely to be temporally proximal to them (level 3 in box 1).

These socioeconomic status variables do not have a direct effect on children's respiratory tracts but are likely to exert their influence through variables such as smoking among other factors such as outdoor air pollution ${ }^{31}$ and damp, cold housing. ${ }^{32}$ Thus, maternal smoking was placed as the most proximal variable in the conceptual model (level 4 in box 1).

\section{Testing the conceptual framework}

The conceptual framework was tested using data on children whose families participated in the 2001 sweep of the FACS. ${ }^{25}$ FACS is a refreshed panel survey that started in 1999 with annual surveys of which the 2001 sweep is the third. The study was extended in 2001 to include a representative sample of all British households with dependent children aged $0-18$ years. The responding parent or guardian (from here on referred to as the mother as $94 \%$ of respondents were mothers) was interviewed in the home using a structured interview schedule including household relationships and sociodemographics, child and adult health, and maternal smoking behaviour.

\section{Outcome of interest}

Data on longstanding respiratory illness were extracted from the dataset. The presence of any longstanding illness or disability in each of the children in the household was ascertained by the following question: Does (child's name) have any longstanding illness or disability? Positive responses were followed up with a question on the nature of the longstanding illness/disability including chest and/or breathing problems, asthma, bronchitis. A dichotomous variable for each child in the household was created (longstanding respiratory problems: yes/no).

\section{Socioeconomic status variables}

Maternal education was defined by educational qualifications obtained from the age of 16 years. To represent the lowest end of the educational spectrum, the variable was dichotomised into no qualifications compared with qualifications from the age of 16 years. Lone parenthood was defined as

Box 1 Conceptual hierarchical framework of risk factors for longstanding respiratory problems in children

- Level 1: maternal education

- Level 2: lone parenthood

- Level 3: material hardship

- Level 4: maternal smoking

Children's longstanding respiratory problems
Table 1 Characteristics of children studied

\begin{tabular}{lll}
\hline & $\begin{array}{l}\text { Number of children } \\
0-2 \text { years exposed }(\%) \\
(\mathbf{n}=2409)\end{array}$ & $\begin{array}{l}\text { Number of children } \\
3-11 \text { years exposed (\%) } \\
\text { (n=7926) }\end{array}$ \\
\hline $\begin{array}{l}\text { Maternal education } \\
\text { No qualifications } \\
\text { Lone parenthood }\end{array}$ & $326(13.5)$ & $1200(15.1)$ \\
$\begin{array}{l}\text { Yes } \\
\text { Household hardship }\end{array}$ & $557(23.1)$ & $2194(27.9)$ \\
$\begin{array}{l}\text { Severe } \\
\text { Maternal smoking }\end{array}$ & $326(13.5)$ & $976(12.3)$ \\
$\begin{array}{l}\text { Current } \\
\text { Sex of children }\end{array}$ & $870(36.1)$ & $2641(33.3)$ \\
$\begin{array}{l}\text { Male } \\
\text { Female } \\
\text { Dependent children }\end{array}$ & $1263(52.4)$ & $4098(51.7)$ \\
1 & $1146(47.6)$ & $3818(48.3)$ \\
2 & $870(36.1)$ & $1258(15.9)$ \\
$>2$ & $930(38.6)$ & $3712(46.8)$ \\
\hline & $609(25.3)$ & $2956(37.3)$ \\
\hline
\end{tabular}

those households headed by a single parent whether never married, widowed, separated, or divorced. The measure of material hardship, developed in the FACS (appendix E in Vergeris $e t \mathrm{al}^{25}$ ), was based on nine variables: $\geqslant 2$ problems with accommodation and cannot afford repairs if home owner; overcrowding; cannot afford to keep home warm; frequent money worries and runs out of money most weeks; no bank account and has $\geqslant 2$ debts; relative material deprivation score on food items in highest $7.5 \%$; relative material deprivation score on clothing items in highest 7.5\%; relative material deprivation score on consumer durables in highest 7.5\%; relative material deprivation score on leisure activities in highest $7.5 \%$. Family scores on hardship (zero to nine) were categorised into three levels of hardship: no hardship-zero on the nine point scale; moderate hardshipone or two on the scale; severe hardship - three or more on the scale. For the purposes of this study, material hardship was dichotomised into severe hardship compared with moderate or no hardship.

\section{Maternal smoking}

Data were available on maternal smoking habits past and present. A series of questions elicited whether the mother was a current or previous smoker and, if current, how many cigarettes she smoked daily. Maternal smoking was categorised for this study into current smoker compared with previous/never smoker.

\section{Confounding variables}

All models were adjusted for other potential confounding variables not included in the conceptual hierarchical framework. These were age of child in years, sex of child, and number of dependent children.

\section{Analysis}

To account for the greater impact of maternal smoking on respiratory disease in infants than older children, ${ }^{5}$ separate but identical analyses were carried out for children aged 0-2 and 3-11 years. Associations between predictor variables, adjusted for age, sex, and number of dependent children, were estimated by logistic regression analysis.

Hierarchical logistic regression models were fitted on longstanding respiratory problems in children $0-2$ and 311. Model 1 represents the effect of maternal education on longstanding respiratory problems adjusted only for age and sex of the child and number of dependent children in the household. Lone parenthood is added to model 2 and shows the effect of lone parenthood on longstanding respiratory 
Table 2 Hierarchical logistic regression models fitted on longstanding respiratory problems in children aged $0-2$ years

\begin{tabular}{|c|c|c|c|c|}
\hline & $\begin{array}{l}\text { Model } 1^{*} \text { : maternal } \\
\text { education alone }\end{array}$ & $\begin{array}{l}\text { Model } 2^{*} \text { : maternal } \\
\text { education and lone } \\
\text { parenthood }\end{array}$ & $\begin{array}{l}\text { Model } 3^{*} \text { : maternal } \\
\text { education, lone } \\
\text { parenthood, and } \\
\text { material hardship }\end{array}$ & $\begin{array}{l}\text { Model } 4^{*} \text { : maternal } \\
\text { education, lone } \\
\text { parenthood, material } \\
\text { hardship, and } \\
\text { smoking }\end{array}$ \\
\hline Maternal education & $1.87(1.14,3.07)$ & $1.43(0.87,2.36)$ & $1.34(0.80,2.22)$ & $1.20(0.72,2.01)$ \\
\hline Lone parenthood & - & $3.35(2.18,5.13)$ & $2.99(1.91,4.68)$ & $2.44(1.53,3.89)$ \\
\hline Material hardship & - & - & $1.57(0.95,2.60)$ & $1.46(0.88,2.42)$ \\
\hline Maternal smoking & - & - & - & $2.04(1.30,3.20)$ \\
\hline
\end{tabular}

problems adjusted for the confounding role of maternal education and the effect of maternal education that is not mediated through lone parenthood. Model 3 shows the effect of material hardship on longstanding respiratory problems adjusted for confounding roles of maternal education and lone parenthood, the effect of lone parenthood not mediated through material hardship, and the effect of maternal education not mediated through lone parenthood or material hardship. Model 4 represents the effect of maternal smoking on longstanding respiratory problems adjusted for the confounding roles of maternal education, lone parenthood and material hardship, the effect of material hardship not mediated through maternal smoking, the effect of lone parenthood not mediated through material hardship and maternal smoking, and the effect of maternal education not mediated through lone parenthood, material hardship, and maternal smoking. All analyses were carried out in SPSS vl0 (SPSS, Chicago, IL).

\section{RESULTS}

Data were available on 10335 children aged $0-11$ years (2409 0-2 years; $79263-11$ years) in 8541 households. Table 1 shows the characteristics of the children in the households studied. Children 3-11 were slightly more likely to live in households with mothers who had no educational qualifications and were lone parents but marginally less likely to be experience severe hardship or be exposed to maternal tobacco smoke. Boys were over-represented in both age groups and the older children were much less likely to be only children. In the age group $0-2$ years, 96 children $(4.0 \%)$ were reported by their parents to have longstanding respiratory problems and 664 children $(8.4 \%)$ in the age group 3-11 years.

The predictor variables were strongly associated with each other in logistic regression models adjusted for age and sex of the child, and number of dependent children. Mothers with no educational qualifications were more than twice as likely to be lone parents, over four times as likely to be in severe material hardship, and three times as likely to smoke. Lone parents had a fivefold increased risk of being in severe material hardship and a fourfold increased risk of being a current smoker. Mothers experiencing severe material hardship were three times more likely to be current smokers.

\section{Infants $\mathbf{0 - 2}$ years}

Having a mother with no educational qualifications, unadjusted for mediating variables, increased the risk of longstanding respiratory problems in infants 0-2 (model 1 , table 2$)$ by $87 \%$ (95\%CI 14, 207). Half this effect was mediated through lone parenthood and lone parenthood increased the risk of longstanding respiratory problems by $235 \%(95 \%$ CI 218,413$)$ when adjusted for confounding by maternal education (model 2, table 2). Adding severe material hardship in model 3 (table 2) resulted in further mediation of the effect of maternal education and mediation of some of the effect of lone parenthood. Severe material hardship when adjusted for confounding by maternal education and lone parenthood increased the risk of longstanding respiratory problems in infants $0-2$ by $57 \%$ (95\%CI 0.95, 160) (model 3, table 2). In the final model (model 4, table 2), the effect of maternal education was further attenuated by the mediating effect of maternal smoking. Some of the effect of both lone parenthood and severe material hardship was mediated through maternal smoking and maternal smoking increased the risk of longstanding respiratory problems by $104 \%(95 \%$ CI 30,220$)$ after adjustment for confounding by maternal education, lone parenthood, and severe material hardship.

\section{What this paper adds}

The paper clarifies the relation between low maternal education, lone parenthood, material hardship, and maternal smoking and how they combine to increase the risk of longstanding respiratory problems in infancy and early childhood. It shows the importance of social context in relation to maternal smoking.

Table 3 Hierarchical logistic regression models fitted on longstanding respiratory problems in children aged $3-11$ years

\begin{tabular}{|c|c|c|c|c|}
\hline & $\begin{array}{l}\text { Model } 1^{*} \text { : maternal } \\
\text { education alone }\end{array}$ & $\begin{array}{l}\text { Model 2*: maternal } \\
\text { education and lone } \\
\text { parenthood }\end{array}$ & $\begin{array}{l}\text { Model } 3^{*} \text { : maternal } \\
\text { education, lone } \\
\text { parenthood, and } \\
\text { material hardship }\end{array}$ & $\begin{array}{l}\text { Model } 4^{*} \text { : maternal } \\
\text { education, lone } \\
\text { parenthood, material } \\
\text { hardship, and } \\
\text { smoking }\end{array}$ \\
\hline Maternal education & $1.46(1.19,1.79)$ & $1.40(1.14,1.73)$ & $1.33(1.08,1.64)$ & $1.32(1.06,1.63)$ \\
\hline Lone parenthood & - & $1.22(1.02,1.45)$ & $1.11(0.93,1.34)$ & $1.10(0.91,1.32)$ \\
\hline Material hardship & - & - & $1.52(1.20,1.91)$ & $1.50(1.19,1.90)$ \\
\hline Maternal smoking & - & - & - & $1.06(0.88,1.26)$ \\
\hline
\end{tabular}




\section{Children 3-11 years}

Hierarchical logistic regression models fitted on longstanding respiratory problems in children 3-11 (table 3) showed different relations among the predictor variables. Maternal education, unadjusted for mediating variables, was associated with a $46 \%(95 \%$ CI 19,79$)$ increase in longstanding respiratory problems in this age group (model 1 , table 3 ). Very little of this effect was mediated through lone parenthood (model 2, table 3). Lone parenthood increased the risk of longstanding respiratory problems by $22 \%$ (95\%CI $2,45)$ when adjusted for confounding by maternal education (model 2, table 3). Material hardship mediated very little of the effect of maternal education but half the effect of lone parenthood and increased the risk of longstanding respiratory problems by $52 \%(95 \%$ CI 20,91$)$ after adjustment for maternal education and lone parenthood (model 3, table 3). Maternal smoking did not mediate the effects of maternal education, lone parenthood, or material hardship and only increased the risk of longstanding respiratory problems by $6 \%$ $(95 \%$ CI $0.88,26)$ when adjusted for maternal education, lone parenthood, and material hardship (model 4, table 3).

\section{DISCUSSION}

Using a conceptual hierarchical framework approach, ${ }^{22}$ this study provides new insights into the complex interrelation of maternal education, lone parenthood, material hardship, and maternal smoking and their combined impact on longstanding respiratory problems in childhood. The interrelations vary with the age group studied. Among infants $0-2$ years, much of the effect of maternal education on longstanding respiratory problems is mediated through lone parenthood, material hardship, and maternal smoking while among children 3-11 years only a small proportion of the effect is mediated. Lone parenthood has a small effect on longstanding respiratory problems in children 3-11 years that is largely mediated through material hardship but, in infants 0-2 years, its effect is larger and only partially mediated through material hardship and maternal smoking. Material hardship, adjusted for maternal education and lone parenthood, has a similar magnitude of effect in both age groups that is minimally mediated by maternal smoking. Maternal smoking increases the risk of longstanding respiratory problems twofold among infants $0-2$ after adjustment for the more distal variables in the hierarchical model but has very little effect, after adjustment, on the risk among children 3-11 years.

\section{Comparison with previous studies}

Few previous studies have used a conceptual hierarchical framework approach to explore these relations in relation to childhood respiratory illness. Baker et $a l^{6}$ used the method to study the relation among deprivation variables (housing tenure and maternal education), crowding variables (ratio of persons per room and parity), and behaviour variables (maternal smoking and duration of breast feeding) and wheeze in infants up to the age of 6 months. After adjustment for confounding by deprivation variables and

\section{Policy implications}

Current policy related to childhood respiratory illness lays main emphasis on the need to reduce children's environmental smoke exposure. The results of this paper suggest that policy measures aimed at improving maternal education and reducing material hardship among households with children are likely to be needed alongside interventions aimed at reducing environmental smoke exposure crowding variables in hierarchical logistic regression models, maternal smoking was associated with an increased risk of wheeze $(1.38$ (95\%CI $1.21,1.58))$. This study shows a greater effect of maternal smoking but this may be related to different outcome definitions and age groups as well as inclusion of different proximal variables in the hierarchical framework.

The findings of this study are consistent with systematic review evidence ${ }^{5}$ that the effect of maternal smoking is greater in infants than in older children. However, this study does not support Cook and Strachan's conclusion ${ }^{4}$ that the effect of maternal smoking is not significantly confounded by socioeconomic status variables. By using a hierarchical conceptual framework, this study shows the complex interrelation of these more distal variables with maternal smoking as a proximal variable exerting a direct effect on the respiratory tract. In addition, the findings suggest that proximal variables, other than maternal smoking, not measured in this dataset, such as damp, mould, and other sources of outdoor and indoor air pollution, ${ }^{31}{ }^{32}$ may be mediating the effects of the distal socioeconomic variables.

The expected associations of maternal smoking reported by previous studies with maternal education, ${ }^{12}$ lone parenthood, ${ }^{33}$ and material hardship, ${ }^{13}$ are confirmed by this study. The strength of these relations reinforces the research imperative to study maternal smoking in its social context and is consistent with Hee-Jin Jun et al's finding that, for low income white women, raising children in the context of economic hardship amplified the risk of cigarette smoking. ${ }^{20}$

\section{Limitations of the study}

This study has several limitations. The study is cross sectional so that causal inferences cannot be made. Maternal smoking, a key predictor variable, was dependent on self report not confirmed by objective measures. Although this may have resulted in misclassification bias, the validity of self report has been shown to be generally acceptable except in pregnancy. ${ }^{34}$ The outcome of interest was also dependent on maternal report and not validated by physician reports. It has been suggested that self report of illness may be systematically biased by social group. ${ }^{35}$ If such a bias were operating in this study, it might exaggerate the association of longstanding respiratory problems with socioeconomic variables. However, studies based on parent report show the expected social gradient in a range of outcomes, ${ }^{36-38}$ have been reported to distinguish healthy children from those with asthma, ${ }^{39}$ show an association with objective measures of respiratory function, ${ }^{40}$ and form the basis of international estimates of asthma prevalence. ${ }^{41}$

A further problem is the absence of data related to other potential proximal variables that may be mediating the effect of the socioeconomic status or exerting an effect independent of confounding by these distal variables. Smoking by household members other than the child's mother may be an important proximal variable. However, as maternal smoking has the greatest effect on young children's respiratory health, ${ }^{45}$ the absence of these data is unlikely to bias the associations among the variables included in the conceptual framework. Children 11 years and under were chosen for inclusion in this study to avoid the potential for confounding by children's own cigarette smoking of the relation of maternal smoking with respiratory problems.

\section{CONCLUSIONS}

Given these limitations, the study findings cannot be interpreted as definitive validation of the conceptual framework from maternal education through lone parenthood, material hardship, and maternal smoking to longstanding respiratory problems in infancy and childhood. However, the 
findings support the conclusion that maternal smoking may have a different effect on respiratory health in infancy compared with later childhood. Furthermore they suggest that maternal smoking is unlikely to act as an isolated risk factor but is embedded in the social circumstances of households forming the proximal end of a chain of risk through which more distal factors such as maternal education, lone parenthood, and material hardship exert their effect on infants' and children's respiratory health. Thus, reducing longstanding respiratory problems in childhood will require public health interventions that aim to alleviate the social circumstances that sustain maternal smoking.

\section{ACKNOWLEDGEMENTS}

Thanks are due to Professor Alan Marsh and Dr S McKay, the principal investigators in the family and children study and to the UK Data Archive at the University of Essex for permission to access and use the data.

Funding: none.

Conflicts of interest: none.

\section{REFERENCES}

1 Cook DG, Strachan DP. Health effects of passive smoking 10: summary of effects of parental smoking on the respiratory health of children and implications for research. Thorax 1999;54:357-66.

2 US Department of Health and Human Services. The health consequences of smoking: a report of the surgeon general, US Department of Health and Human Services, Centers for Disease Control and Prevention, National Center for Chronic Disease Prevention and Health Promotion, Office of Smoking and Health, 2004

3 World Health Organisation. International consultation on environmental tobacco smoke and child health: consultation report. Geneva: WHO, Division of Non-Communicable Diseases, Tobacco Free Initiative, 1999.

4 Strachan DP, Cook DG. Parental smoking and lower respiratory illness in infancy and early childhood. Thorax 1997;52:905-14.

5 Cook DG, Strachan DP. Parental smoking and prevalence of respiratory symptoms and asthma in school-aged children. Thorax 1997:52:1081-96.

6 Baker D, Taylor H, Henderson J. Inequality in infant morbidity: causes and consequences in England in the 1990s. ALSPAC Study Team. Avon longitudinal study of pregnancy and childhood. J Epidemiol Community Health 1998;52:451-8.

7 Burr ML, Miskelly FG, Butland BK, et al. Environmental factors and symptoms in infants at high risk of allergy. J Epidemiol Community Health 1989;43:125-32.

8 Dales RE, Choi B, Chen Y, et al. Influence of family income on hospital visits for asthma among Canadian school children. Thorax 2002;57:513-17.

9 Cesaroni G, Farchi S, Davoli M, et al. Individual and area-based indicators of socioeconomic status and childhood asthma. Eur Resp J 2003;22:619-24.

10 Mielck A, Reitmeir P, Wjst M. Severity of childhood asthma by socioeconomic status. Int J Epidemiol 1996:25:388-93.

11 Strachan DP, Anderson HR, Limb ES, et al. A national survey of asthma prevalence, severity, and treatment in Great Britain. Arch Dis Child 1994;70:174-8.

12 Centers for Disease Control, Prevention (CDC). Cigarette smoking among adults - United States, 2002. Morb Mortal Wkly Rep 2004:53:427-31.

13 Graham H, Blackburn C. The socio-economic patterning of health and smoking behaviour among mothers with young children on income support. Sociology of Health and Illness 1998;20:215-40.

14 Graham H, Der G. Patterns and predictors of tobacco consumption among women. Health Educ Res 1999;14:611-18.

15 Power C, Graham H, Due P, et al. The contribution of childhood and adult socioeconomic position to adult obesity and smoking behaviour: an international comparison. Int J Epidemiol 2005; 19:335-44.

16 Barbeau EM, Krieger N, Soobader MJ. Working class matters: socioeconomic disadvantage, race/ethnicity, gender, and smoking in NHIS 2000. Am J Public Health 2004;94:269-78.
17 Graham H. Women's smoking and family health. Soc Sci Med 1987;25:47-56.

18 Greaves L. Smoke Screen: women's smoking and social control. Halifax, Nova Scotia: Scarlet Press, 1996.

19 Stewart MJ, Brosky G, Gillis A, et al. Disadvantaged women and smoking. Can J Public Health 1996;87:257-60.

20 Hee-Jin Jun, Subramanian SV, Gortmaker S, et al. Socio-economic disadvantage, parenting responsibility and women's smoking in the United States. Am J Public Health 2004;94:1270-6.

21 Kaplan GA. Where do shared pathways lead? Some reflections on a research agenda. Psychosom Med 1995;57:208-12.

22 Victora CG, Huttly SR, Fuchs SC, et al. The role of conceptual frameworks in epidemiological analysis: a hierarchical approach. Int J Epidemiol 1997; 26:224-7.

23 White IR, Blane D, Morris JN, et al. Educational attainment, deprivationaffluence and self-reported health in Britain: a cross-sectional study. $J$ Epidemiol Community Health 1999:53:535-41.

24 Séguin $L, X \cup Q$, Gauvin $L$, et al. Understanding the dimensions of socioeconomic status that influence toddler's health: unique impact of lack of money for basic needs in Quebec's birth cohort. J Epidemiol Community Health 2005:59:42-8.

25 Vegeris S, Perry J. Families and children 2001: living standards and the children. Research report 190. London: Corporate Document Services on behalf of Department for Work and Pensions, 2003.

26 Krieger N, Williams DR, Moss NE. Measuring social class in US public health research: concepts, methodologies and guidelines. Annu Rev Public Health 1997; 18:341-78

27 Cavelaars AE, Kunst AE, Geurts JJ, et al. Persistent variations in average height between countries and between socio-economic groups: an overview of 10 European countries. Ann Hum Biol 2000;27:407-21.

28 Koupilová I, Vågerö D, Leon DA, et al. Social variation in size at birth and preterm delivery in the Czech Republic and Sweden, 1989-91. Paediatr Perinat Epidemiol 1998;12:7-24.

29 Kilkey M, Bradshaw J. Lone mothers, economic well-being and policies. In: Sainsbury D, ed. Gender and welfare state regimes. Oxford: Oxford University Press, 1999: 147-84

30 Adelman L, Middleton S, Ashworth K. Britain's poorest children: severe and persistent poverty and social exclusion. London: Centre for Research in Social Policy with Save the Children UK, Save the Children, 2003

31 Elliott MR, Wang Y, Lowe RA, et al. Environmental justice: frequency and severity of US chemical industry accidents and the socioeconomic status of surrounding communities. J Epidemiol Community Health 2004;58:24-30.

32 Bornehag CG, Sundell J, Sigsgaard T. Dampness in buildings and health $(D B H)$ : report from an ongoing epidemiological investigation on the association between indoor environmental factors and health effects among children in Sweden. Indoor Air 2004;14(suppl 7):59-66.

33 Jaakkola N, Ruotsalainen R, Jaakkola JJ. What are the determinants of children's exposure to environmental tobacco smoke at home? Scand J Soc Med 1994;22:107-12.

34 Patrick D, Cheadle A, Thompson D, et al. The validity of self-reported smoking: a review and meta-analysis. Am J Public Health 1994;84:1086-93.

35 Blane D, Power C, Bartley M. Illness behaviour and the measurement of class differentials in morbidity. Journal of the Royal Statistical Society $A$ 1996;159:77-92.

36 Spencer NJ, Coe C. Parent-reported longstanding illness problems in early childhood: a cohort study. Arch Dis Child 2003;88:570-3.

37 Spencer NJ. Does material disadvantage explain the increased risk of adverse health, educational, and behavioural outcomes among children in lone parent households in Britain? A cross sectional study. J Epidemiol Community Health 2005;59:152-7.

38 Riley AW, Forrest CB, Starfield B, et al. The parent report form of the CHIPchild edition: reliability and validity. Med Care 2004;42:210-20.

39 Varni JW, Burwinkle TM, Rapoff MA, et al. The Peds QL in pediatric asthma: reliability and validity of the pediatric quality of life inventory generic core scales and asthma module. J Behav Med 2004;27:297-318.

40 Hoek G, Wypii D, Brunekreef B. Self-reporting versus parental reporting of acute respiratory symptoms of children and their relation to pulmonary function and air pollution. Int J Epidemiol 1999;28:293-9.

41 Pearce N, Sunyer J, Cheng S, et al. Comparison of asthma prevalence in the ISAAC and ECRHS. ISAAC Steering Committee and the European Community Respiratory Health Survey. International study of asthma and allergy in childhood. Eur Respir J 2000;16:420-6. 